\title{
AUTOMATIC COLLISION DETECTION FOR AN AUTONOMOUS ROBOT USING PROXIMITY SENSING TECHNOLOGY ON AN AVR HARDWARE PLATFORM
}

\author{
Anish Kumar ${ }^{1}$, Ramandeep Singh ${ }^{2}$ \\ ${ }^{1} P G$ Student M.Tech (ES), EECE Department, ITM University, Gurgaon, Haryana, India \\ ${ }^{2}$ Assistant Professor, EECE Department, ITM University, Gurgaon, Haryana, India
}

\begin{abstract}
This work is concerned about making an anti-collision device. Primary goal of anti-collision device is to identify the collision and report it to control panel. Automatic collision detection is an advance area of research. Collision are catastrophic and a mass destructive force. This will harm property and life both. Now day collision detection is the one of most important algorithm used in autonomous vehicle development phases. Actuator takes Input through sensor module. To belt that system, we are using proximity sensor, AVR controller and motors. This program code simulated using proteus software as real like environment to identifying anti-collision.
\end{abstract}

Keywords: AVR microcontroller, Proximity Sensor, Protus, Anti-Collision System, Autonomous Vehicle, Actuator.

\section{INTRODUCTION}

Every mechanism, which having moving parts, needs some safety measure. The human error or system failure with machine raises the happening of undesired events. Our purpose to work on anti-collision device is to make an anti collision zone, make device portable. Other factor can also be involved like high speed response and low cost. Collision avoidance is one of the most difficult domains of intelligent vehicle. This is also known as pre-clash or forward collision warning system. Various sensor are used in making of anti collision system i.e. laser, camera, radar, ultrasonic, GPS etc. to detect the eminent crash [1] [5]. Once the detection has been done this system warn the driver or action is taken through actuators without driver interference. The different actuators are like servo motor, relays, driving wheel and breaks etc.

A collision detection system is an automatic self driven system for the safety. Such system is designed to reduce the surveillance of accident. The major hardware part of the system will be camera, sensor, and microcontroller [1] [3] [7] [10]. System is designed in such a manner so that it should be more reliable and efficient for detecting not only the imminent crash but also low cost and power efficient system[11][12]. As soon as the detestation is there the system either warn or will take imminent action without driver input.

It is one of the major parts of autonomous vehicles. As an autonomous vehicle, it is capable of sensing its environment and navigating without human input. Zigbee is also one of the cheap technology is being used as a communication service provider between the nodes [2] [4] [7] [10].Zigbee has defined data rate of $250 \mathrm{kbps}$. The GPS and GSM technologies being merged with collision detection algorithms for better reliability [6] [11] Robotic cars exist mainly as prototypes and demonstration systems. We can take any technique for taking input from external world like.

Simulation is being done on proteus [5]. Purpose of simulating the design is presenting the possibilities for its implementation like robots, cars, railway etc [5] [8]. Also ARM based processer is being used for making ACD (Anti Collision Detection) [6] [10]. Collision can be vehicle to vehicle or can be vehicle to infrastructure. Intra-vehicle communication between two different vehicles will help in detecting and avoiding collision [9].

\section{BLOCK DIAGRAM}

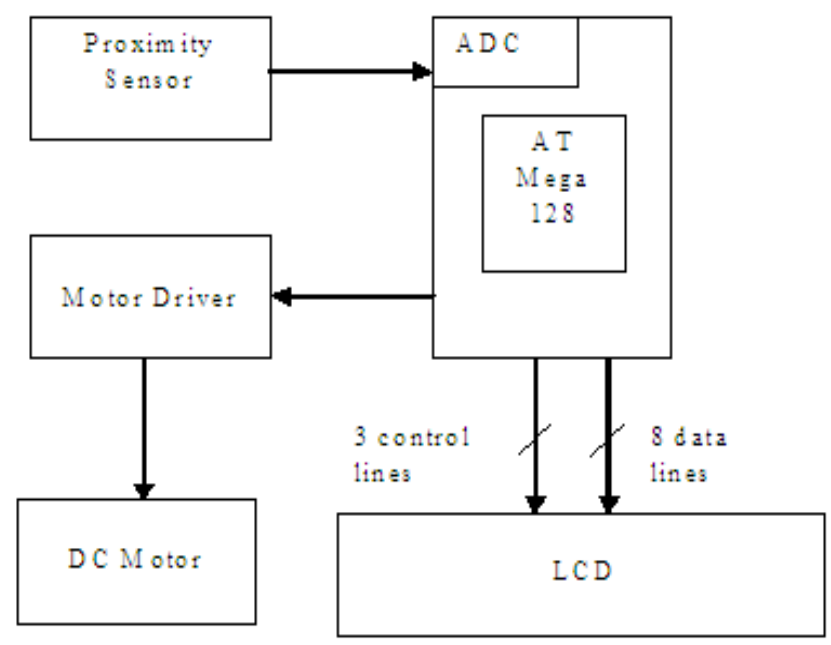

Fig-1: Block Diagram of collision detection using proximity sensor 
One block diagram shows the flow of data in different sections. In block diagram there are shown six blocks proximity sensor, ADC, ATMEGA board, motor driver circuit, DC motor and LCD. All development blocks in a single platform they communicate with external world through sensor array with its very first block. That analog input will be processed by the ADC in ATMEGA board. An motor driver circuit is used for the proper functioning of the DC motor driver circuit takes the output from the ports of the ATMEGA board and drive the motor next connected to it. Because signal coming out of the controller are not well enough to drive the motor so in that case motor driver helps in. One LCD unit is also been there for displaying the activation of motor like is that motor in stop, run, clockwise or anticlockwise condition. As in here we are using proximity sensor which helps in detecting low range collision. Microcontroller selection requires sufficient input/output control lines, processing speed and adequate memory for running the entire program and additional serial ports, Timers, counters, PWM etc. We are choosing AVR AT mega 128 controllers. It's a 8 bit controller based on advance RISC architecture, highly endure non-volatile memory segment and with all special feature like power-on reset, Internal Calibrated RC Oscillator, External and Internal Interrupt Sources, Six Sleep Modes, ADC Noise Reduction, Power-save, Power-down, Standby, and Extended Standby, Software Selectable Clock Frequency etc. In sensor block we can use any module of sensor according to the design application. The selection of ADC using is according to the sensitivity we required like 10,12 , 16 bits. In the controller block we are using ATmega128 development board.

\section{FLOW CHART/ALGORITHM}

Flow chart represent that how data will flow and when the decision time comes. How system will react to the situation when more than one decision has to make. Action will be taken in which sequence. After starting two decision blocks one is of active transmission and other is of receiver. Transmission block is in loop with starting till they are not active when this will active decision comes to receiver. That decision is in loop with the output of transmitter. In this flowchart from starting we check for the sensor array is active or not then if value is send by the received then correspondent output will be fetch on the port. Next we choose the concept of port to port transfer of data. We do control the operation of DC motor. We are using a sensor module. The sensor module needs $5 \mathrm{~V}$ for their operation. Output signal will be in form of voltage level. That voltage level we are getting on ADC. ADC converts that voltage signal into binary output. Respectively binary output has been taken on the port. According to the port value. We select the values for motor operation on other port. Values for motor port is designed by using if else condition. As we can see in flow chart process block of motor are connected with decision blocks using if-else statement.

We are designing algorithm in such a way so that when there is no object our robot run freely in straight line and according to the intensity of signal coming from sensor response of the robot will be different i.e. start, turn right, turn left, stop etc.

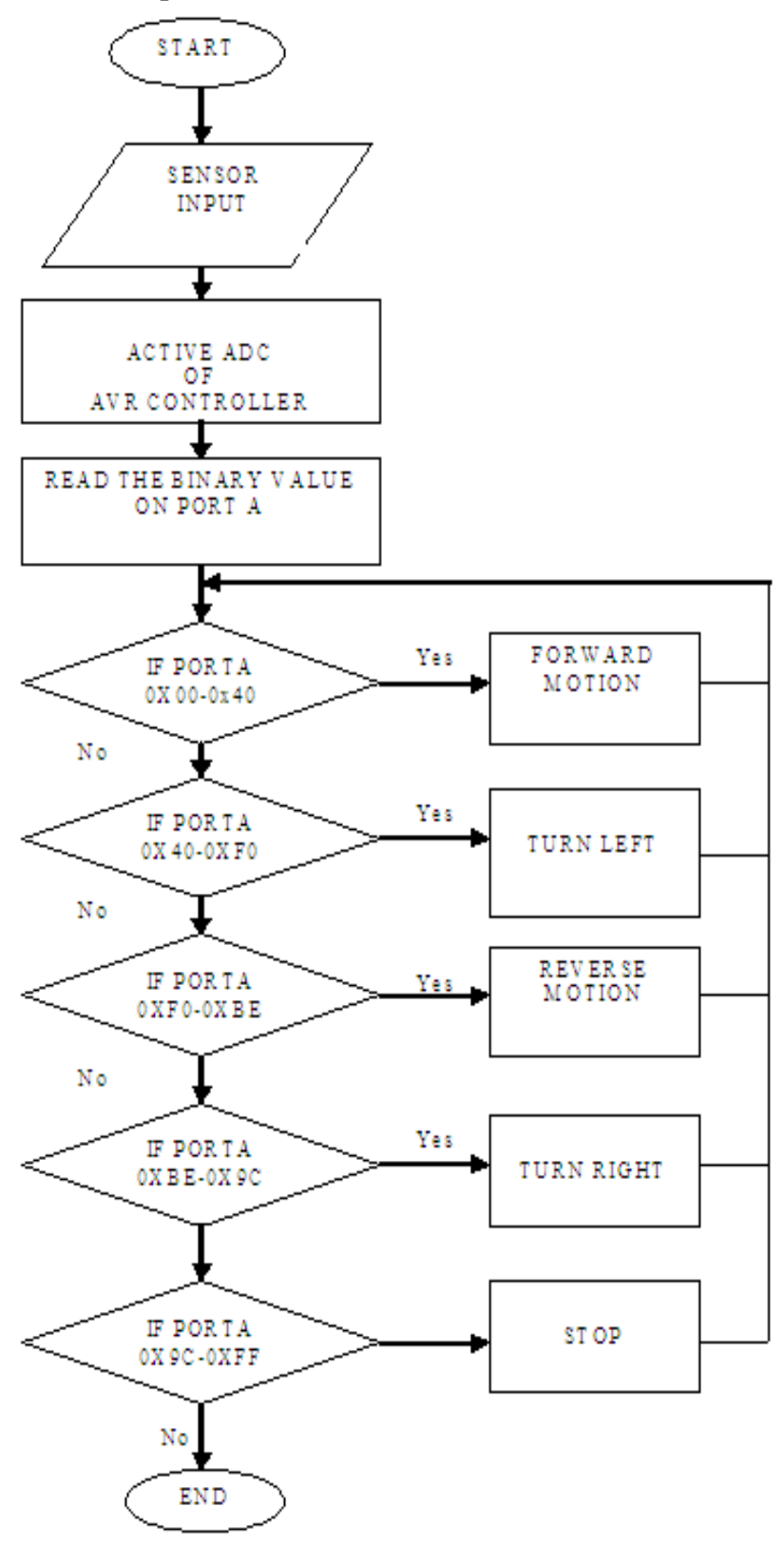

Fig-2: Flow Chart

They are continuously in loop. One time only one process block of motor is active. That is chosen accordingly what our sensor is capturing.

In above flow chart sensor takes the information. That is, is the object being placed on the way as obstacle? Then it inform to the brain of the system (to processer) whose purpose is to start and stop the motor accordingly. A continuous collision detection algorithm is there. The algorithm is designed in such a way so that for any detection of collision system get alert. First it will respond in the form of error then stop or change its direction. We can also increase the number of sensor input to microcontroller like left sensor unit, right sensor unit, front and back unit for robot car for make it more reliable. 


\section{PROTEUS SIMULATION SOFTWARE:}

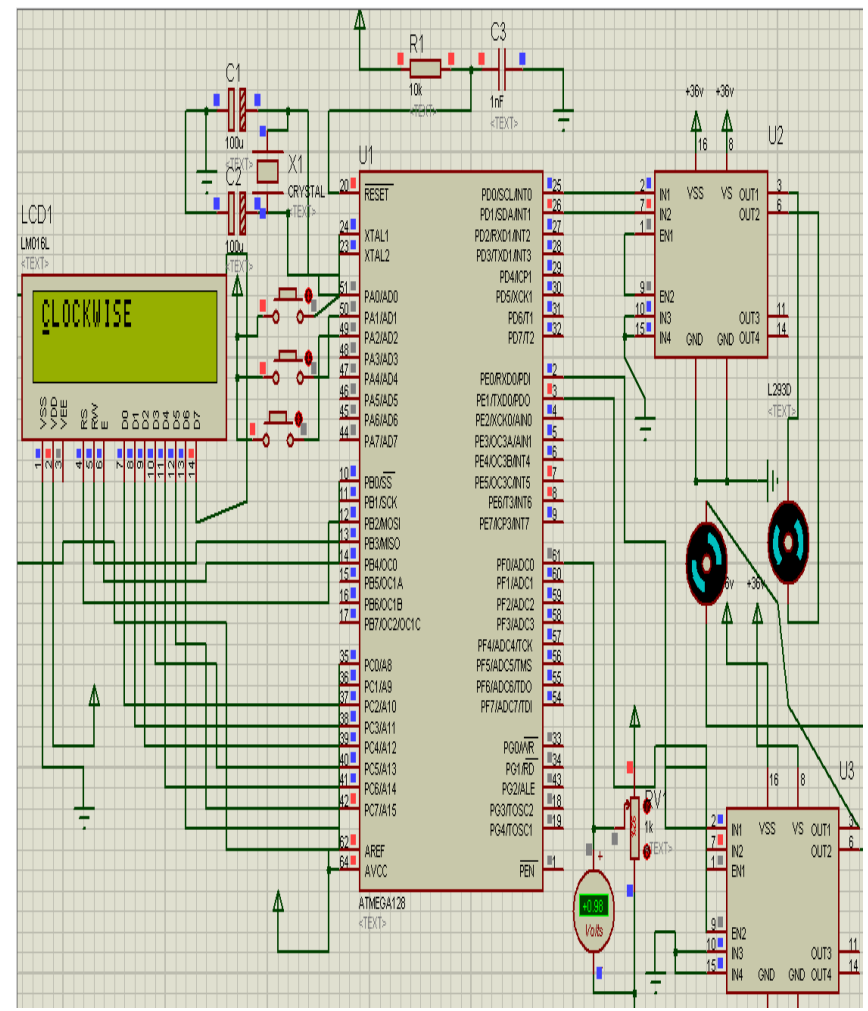

Fig-3: Simulation on Proteus

\section{APPLICATION AREA}

There are verities of application of an automatic collision detection device. Some of them are like in space application, an intelligent self driven car, railway and metro automation, intelligent robots, traction control system, dynamic steering response, intelligent parking, traffic signal recognition, intelligent speed adaptive system.

There are endless scopes of this idea. This idea is easy adaptable with latest technology. We can merge different technology for making one of the best automatic collision devices. These devices can use in military, hospitals, traffic control, space application etc.

\section{ADVANTAGES \& LIMITATION}

A vehicle with automatic collision detection system will increase the reliability. It increases capacity $t$ roads and higher speed limit for autonomous car. In autonomous car it would not matter, if the occupant is under age, over age, intoxicated or blind. Not-collision car and autonomous car can go for pick up the passenger without driver. This will also help in reduction the physical road signage. This vehicle can operate themselves in environment like where impossible to go for human and operate themselves automatically.

This system mainly reduces the driver stress if it's a semi automatic or can give warning in advance on dash board. If system is connected with GPS then it's easier to find the condition of roads.
The main disadvantage of the system if that we can't totally depends on system response. Information given by the sensor can mislead the person if the orientation of the sensor and camera is changed from a particular position. The collision detection system is also get effected by the environmental conditions like by dust, fog etc. Algorithm designed will be more complex because multiple tasks are being given to single processer when there are multiple tasks in an autonomous vehicle. Tasks are chosen to be done according to the priority and severity. Response of the system should be in fraction of second otherwise imminent crash can happen.

Vehicle with anti-collision system will increase the cost because it requires additional vehicle equipment, service, maintenance and possibly additional roadway infrastructure. Also additional risk such as system failure, be less reliable under some critical condition etc. Security for information abuse, failure of GPS system can cause problem. Overridden of automatic collision algorithm by manual operation can also creates problem. Collision prevention assistance requires a sufficient radar reflectance of objects and efficiency of sensor are compromised by snow, mud or leaves.

\section{RESULT}

Our system is working for small range of operation and collision is being detected and when collision being detected it might stop or turn as per program develop.

As following the result of motor motion has shown on LCD screen i.e. start, clockwise, anticlockwise, stop etc.

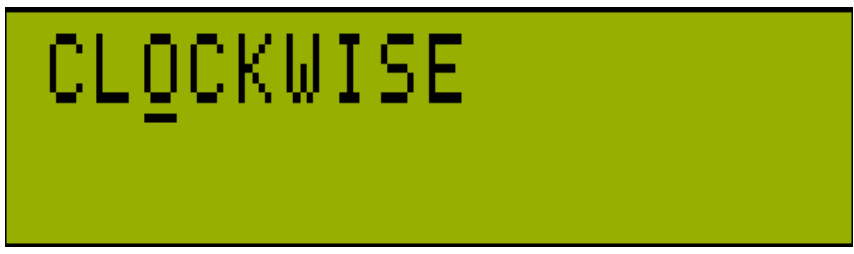

Fig- 4: Interface screen

\section{CONCLUSIONS}

The embedded system for collision detection can ensure the protection and operation of autonomous robots in the condition where zero human interference. If we see this technology with its future there are endless development scope and technology we can merge with it. Everything will became automatic and also sending status information to owner about collision happening or not.

\section{ACKNOWLEDGEMENTS}

I am deeply grateful to the professors, faculties and technical staff of Electrical, Electronics \& Communication Engineering of ITM University, Gurgaon by whose support I was able to complete my research work. I want to thanks my friends also who were involved in their research work and same time they help me with their practical experience. 


\section{REFERENCES}

[1]. Frederic Maire "Vision Based Anti-collision System for Rail Track Maintenance Vehicles", Australia Faculty of IT, Queensland University of Technology.

[2]. Arun P; Sabarinath G; Palai, Kottayam,; Madhukumar S; Careena P "Collision And Level Crossing Protection System for Indian Railways" International Journal of Latest Trends in Engineering and Technology (IJLTET).

[3]. CH. ANUSHA1, CH.V.S.GOPINATH2, P. NAGAMALLAIAH3 "ANTI COLLISION DEVICE BETWEEN TRAINS USING ZIGBEE" International Conference on Electronics and Communication Engineering (ECE) 7th April 2013, Bangalore,ISBN:978-93-82208-84-6. [4]. Arun.P ; Saritha.S ; Madhukumar.S "Simulation of Zigbee based Tacs for Collision Detection and Avoidance for Railway Traffic" Special Issue of International Journal of Computer Applications (0975 - 8887) on Advanced Computing and Communication Technologies for HPC Applications - ACCTHPCA, June 2012.

[5]. SANDHYA GAUTAM;SANDIP NEMADE;TEENA SAKLA "SIMULATION OF AN ANTI-COLLISION SYSTEM ON SAME TRACK FOR RAILWAYS" Sandhya Gautam et. al. /International Journal of Engineering and Technology Vol. 2(9), 2010, 4832-4837.

[6]. J.D.Prathusha, K.S.Roy , Mahaboob Ali “ARM Cortex M3 Based Collision Detection System" International Journal of Engineering Trends and Technology (IJETT) Volume4Issue5- May 2013.

[7]. G.Anjali bissa, S.Jayasudha, R.Narmatha and B.Rajmohan "Train Collision Avoidance System Using Vibration Sensors And Zigbee Technology" IJREAT International Journal of Research in Engineering \& Advanced Technology, Volume 1, Issue 1, March, 2013 ISSN: $2320-8791$.

[8]. Rossi Passarella, Bambang Tutuko \& Aditya P.P. Prasetyo "DESIGN CONCEPT OF TRAIN OBSTACLE DETECTION SYSTEM IN INDONESIA” IJRRAS 9 (3) December 2011.

[9]. Thomas Strang, Michael Meyer zu Hörste, Xiaogang Gu " A RAILWAY COLLISION AVOIDANCE SYSTEM EXPLOITING AD-HOC INTER-VEHICLE COMMUNICATIONS AND GALILEO” German Aerospace Center (1)Institute of Communications and Navigation (2)Institute of Transportation Systems.

[10]. Mr. N. Sambamurthy, Sk. Hasane Ahammad, “ Prevention of Train Accidents Using Wireless Sensor Networks" Int. Journal of Engineering Research and Applications ISSN : 2248-9622, Vol. 3, Issue 6, Nov-Dec 2013, pp.1592-1597.

[11]. Richard W. Wall , Jerry Bennett, Greg Eis, Kevin Lichy, and Elizabeth Owings, "CREATING A LOW-COST AUTONOMOUS VEHICLE” Students, University of Idaho Electrical and Computer Engineering Dept.Moscow.

[12]. Raja Jurdak, Kevin Klues, Brano Kusy, Christian Richter, Koen Langendoen, and Michael Brünig "Opal: A Multiradio Platform for High Throughput Wireless Sensor Networks" IEEE EMBEDDED SYSTEMS LETTERS, VOL. 3, NO. 4, DECEMBER 2011.

\section{BIOGRAPHIES}

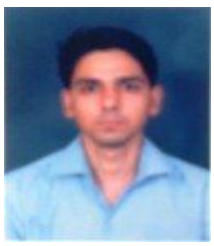

Anish Kumar is currently is doing Post Graduation in Embedded Systems from ITM University, Gurgaon. He completed his B.Tech in Electrical Engineering from Chitkara Institute of Engineering and Technology Rajpura, Chandigarh under Punjab Technical University Jalandher in 2011. His area of interest is Embedded System Design and Real Time Systems.

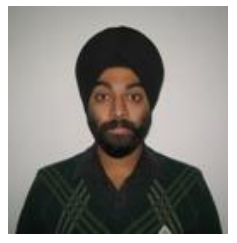

Ramandeep Singh is an Assistant Professor in EECE Department of ITM University, Gurgaon. He is pursuing $\mathrm{PhD}$ in embedded systems from ITM University. In 2009 he has completed M.E. in embedded systems. $\mathrm{He}$ is a B. Tech. graduate from GGSIPU, Delhi. His core research areas are low power embedded systems, robotics, FPGA based embedded systems and SCADA. Prior to joining ITM University he has worked with NXP Semiconductors, Bangalore. He has various publications in international journals and conferences. 